\title{
Comparison of glottic view and ease of orotracheal intubation with Macintosh and McCoy laryngoscopes in anaesthetized adult patients
}

\author{
Arun Kumar Handigodu Duggappa ${ }^{1}$, Shiyad Muhamed ${ }^{2 *}$, Shaji Mathew ${ }^{3}$, Satyanarayana Kuruba \\ Pujari $^{4}$, Manjunath Prabhu ${ }^{5}$, Jayanth Navada ${ }^{6}$ \\ Associate Professor ${ }^{1}$, Assistant Professor ${ }^{2}$, Professor ${ }^{3}$, Professor and Head ${ }^{5}$, Senior Resident ${ }^{6}$, Kasturba \\ Medical College, Manipal Academy of Higher Education, Manipal, India. Assistant Professor ${ }^{4}$,East point \\ College of Medical sciences and research center, Bangalore, India.
}

\begin{abstract}
Background and aims: This study is aimed at comparing glottic view and ease of intubation with Macintosh and $\mathrm{McCoy}{ }^{\mathrm{TM}}$ laryngoscopes in adult patients.

Methods: One hundred forty consenting patients undergoing elective surgery requiring orotracheal intubation were randomly assigned to two groups for assessment of glottic view and ease of intubation. Cormack-Lehane (CL) glottic view, ease of intubation, laryngoscopy time and intubation time were recorded.
\end{abstract}

Results: All recruited patients completed the study, with a single attempt for successful intubation. Demographic profile was comparable between groups. Glottic view represented as CL grade (Macintosh laryngoscope- grade 1 among 100 patients, 2a in 26, 2b in 12 and 3a in 2 patients; $\mathrm{McCoy}^{\mathrm{TM}}$ laryngoscope- grade 1 in $105,2 \mathrm{a}$ in $20,2 \mathrm{~b}$ in 13 and $3 \mathrm{a}$ in 2 patients), requirement of additional manoeuvres like optimal external laryngeal manipulation (OELM)/use of lever for best glottic view (OELM in 40 patients, lever in 35 patients), ease of intubation (Macintosh laryngoscope- grade 1 in 49 patients, grade 2 in 21 patients; $\mathrm{McCoy}^{\mathrm{TM}}$ laryngoscope- grade 1 in 53 patients, grade 2 in 17 patients), mean laryngoscopy time (6.02 $\pm 1.91 \mathrm{~s}$ with Macintosh and $6.65 \pm$ $2.09 \mathrm{~s}$ with $\mathrm{McCoy}^{\mathrm{TM}}$ laryngoscope) and mean intubation time $(15.24 \pm 3.01 \mathrm{~s}$ with Macintosh and $16.09 \pm 3.42 \mathrm{~s}$ with $\mathrm{McCoy}^{\mathrm{TM}}$ laryngoscope) were comparable between laryngoscopes.

Conclusion: In adult patients with essentially normal airway, Macintosh and $\mathrm{McCoy}^{\mathrm{TM}}$ laryngoscopes provide similar glottic view and ease at intubation, with comparable time required for laryngoscopy and intubation when performed by an experienced anaesthesiologist.

Keywords: Airway management; Macintosh; $\mathrm{McCoy}^{\mathrm{TM}}$ laryngoscope; optimal external laryngeal manipulation

\section{Introduction}

Tracheal intubation is most commonly accomplished using conventional Macintosh laryngoscope. Laryngoscopes have undergone tremendous modifications over years, each one with its own merits and demerits. ${ }^{1}$

*Correspondence: Shiyad Muhamed

E mail: shiyad82@gmail.com

https://orcid.org/0000-0003-4431-2324

Received: 15/12/2018

Accepted:09/06/2019

DOI: http://doi.org/10.4038/slja.v27i2.8397
$\mathrm{McCoy}^{\mathrm{TM}}$ laryngoscope (Penlon, Abington, UK) being one such modification, whose curved and levered tip supposedly helps to visualise glottis better in a subset of patients in whom the epiglottis overhangs on glottic aperture or laryngoscopist is alone without additional assistance. ${ }^{2}$ It is designed to be used similar to Macintosh laryngoscope with its distal tip placed in vallecula; activation of lever flexes the distal tip of blade upwards, thus raising epiglottis away from glottis in situations where the operator does not have a satisfactory view of larynx. $^{3}$ In clinical scenarios wherein sniffing position cannot be maintained for conventional laryngoscopy, the $\mathrm{McCoy}^{\mathrm{TM}}$ laryngoscope has been shown to be a very useful device. ${ }^{4,5,6}$ In this study we compared Macintosh and $\mathrm{McCoy}^{\mathrm{TM}}$ laryngoscopes with respect to glottic visualisation and ease of orotracheal intubation. 
Muhamed et al. Sri Lankan Journal of Anaesthesiology: 27(21):151-156(2019)

\section{Subjects and Methods}

This double blinded randomised prospective study was commenced after obtaining approval from hospital ethics committee and registering with Clinical Trial Registry $\quad-\quad$ India (CTRI/2018/03/019154). Adult patients between 18 to 50 years of age, with a body mass index of 18 to $25 \mathrm{kgm}^{2}$, belonging to American Society of Anaesthesiologists Physical Status I and II with modified Mallampati class I and II scheduled for elective surgery requiring orotracheal intubation were enrolled. Patients with anticipated difficult airway, pregnancy, patients at risk of gastric aspiration and those with known pathology involving the upper airway were excluded. Our primary objectives were to compare glottic view and ease of intubation; secondary objectives were to compare laryngoscopy time and intubation time with Macintosh and McCoy ${ }^{\mathrm{TM}}$ laryngoscopes. Two observers were involved in the study. Observer 1

was the postgraduate in anaesthesiology, who evaluated patients preoperatively and selected patients who met inclusion criteria and recorded the study parameters. Observer 2 was an experienced anaesthesiologist non-blinded to the group allocation, performed direct laryngoscopy and intubation and graded the glottic view and ease of intubation. Observer 2 acquired familiarity with use of $\mathrm{McCoy}^{\mathrm{TM}}$ laryngoscope for 2 months before commencing study, as the routinely used laryngoscope in our department is Macintosh laryngoscope. We used laryngoscope size 3 for females and size 4 for male patients. Once the patient was on operation table, standard monitors were connected which included 5-electrode electrocardiogram, pulse oximeter, automated noninvasive blood pressure and peripheral nerve stimulator. Intravenous (IV) cannula of appropriate size was secured. Patients were placed supine with a $7 \mathrm{~cm}$ thick pillow under occiput to achieve sniffing position. Observer 2 preoxygenated the patient with $100 \%$ oxygen for 3 minutes followed by IV induction by observer 1 with fentanyl $2 \mu \mathrm{g} / \mathrm{kg}$ and propofol $2-3 \mathrm{mg} / \mathrm{kg}$. After ensuring ability to mask ventilate, muscle paralysis was achieved with IV vecuronium bromide $0.1 \mathrm{mg} / \mathrm{kg}$. Anaesthesia was deepened with isoflurane adjusted for a minimum alveolar concentration of 1 to 1.2. After train-offour count is zero, direct laryngoscopy was performed with an assorted laryngoscope by observer 2 according to randomisation (Figure 1).

Laryngoscopy time (seconds) starting from introduction of laryngoscope into patient's mouth to adequate exposure of glottic inlet was recorded by observer 1 using a stopwatch. Glottic view was graded without manipulation of lifting force and without external manipulation as per the Cook's modification of Cormack-Lehane (CL)grading system. ${ }^{7}$ Grade 1: most of the glottis is visible; Grade 2a: posterior part of the cords visible; Grade 2b: only arytenoids visible; Grade 3a: epiglottis visible and liftable; Grade 3b: epiglottis adherent to pharynx and not liftable; Grade 4: no laryngeal structures are visible. Whenever glottic view is $>$ CL grade 1, additional manoeuvres like optimal external laryngeal manipulation (OELM in case of Macintosh laryngoscope) or activation of lever (in case of $\mathrm{McCoy}^{\mathrm{TM}}$ laryngoscope) were employed to see whether any improved view can be obtained. During first laryngoscopy, CL grading and laryngoscopy time were recorded. Then bag-mask ventilation with $2 \%$ isoflurane in oxygen for two minutes was done, followed by second laryngoscopy and intubation with assorted scope as per group allocation. The glottic view, laryngoscopy time, ease of intubation and intubation time were recorded during second laryngoscopy (Figure 1). Size of the cuffed endotracheal tube used was $7.0 \mathrm{~mm}$ internal diameter (ID) portex tube for females and $8.0 \mathrm{~mm}$ ID for male patients. Intubation time was defined as the time commencing from insertion of endotracheal tube at mouth to confirmation of correct placement by waveform capnography, as recorded by observer. Ease of intubation was graded as follows. Grade 1: easy intubation; Grade 2: intubation aided by OELM / lever; Grade 3: intubation requiring more than one attempt, but $<3$ attempts and / or use of stylet; Grade 4: failure to intubate in 3 attempts. If the laryngoscopy grade was $>$ CL grade 1, OELM/lever was instituted to facilitate a better view. In case of failure at first intubation attempt with OELM/lever, either attempt was planned to be repeated for a maximum of three times or a stylet was proposed to be used as appropriate. Patients were ventilated with $100 \%$ oxygen in $2 \%$ isoflurane between consecutive attempts at laryngoscopy/intubation to prevent awareness and desaturation. 


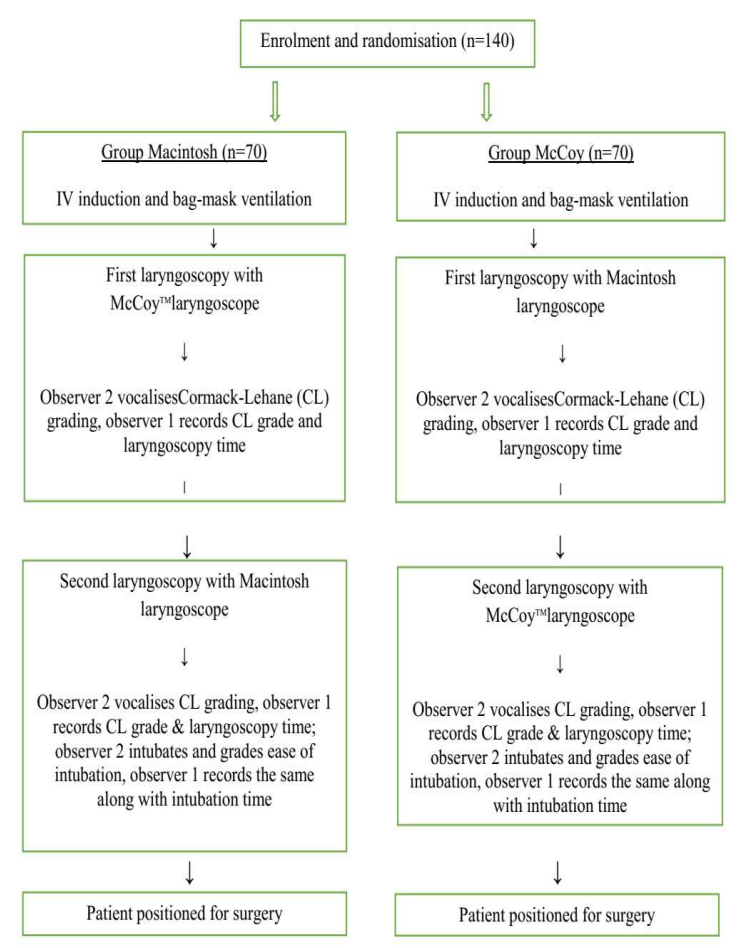

Figure 1: CONSORT flow chart

If three successive intubation attempts with the assigned laryngoscope fail, intubation was planned to be achieved using additional expertise and equipment. Further course of anaesthetic proceeded as per the discretion of anaesthesiologist in-charge of patient.

Sample size was calculated based on a pilot study of 20 patients, with glottic view as primary outcome. For the study to have a power of $90 \%$ at $5 \%$ significance, a sample size of 63 were required in each group. To allow for potential dropouts, we recruited 70 patients in each group. Data analysis was done using Statistical Package for Social Science System for windows version 20 (SPSS Inc. Chicago, USA). Continuous variables were expressed as mean $\pm \mathrm{SD}$. Unpaired t-test was used to analyse laryngoscopy time and intubation time.

\section{Results}

All patients from both groups completed the study. Demographic profiles were comparable between two groups.
Glottic view before and after OELM with Macintosh laryngoscope is compared. (Table 1) One hundred patients had grade $1 \mathrm{CL}$ view. Twenty-six patients had grade $2 \mathrm{a}$ view and 3 patients had grade $2 \mathrm{~b}$ view before OELM, which improved to grade 1 view after OELM. Nine patients had grade $2 \mathrm{~b}$ view initially, which improved to grade 2a after OELM. Two patients had grade $3 \mathrm{a}$ view before OELM, which improved to grade $2 b$ after OELM.

Glottic view before and after using lever with $\mathrm{McCoy}^{\mathrm{TM}}$ laryngoscope is compared. (Table 2) One hundred five patients had grade $1 \mathrm{CL}$ view. Twenty patients had grade 2a view, which improved to grade 1 after employing lever. Nine patients had grade $2 \mathrm{~b}$ view prior to use of lever, which improved to grade 1 after using lever. Four patients had grade $2 \mathrm{~b}$ and 2 patients had grade $3 \mathrm{a}$ view prior to use of lever, which improved to $2 \mathrm{a}$ after using the lever.

The number of patients whose glottic view changed after OELM and activation of lever is compared. (Table 3) With Macintosh laryngoscope, 40 patients had improved glottic view after OELM; change in glottic view by one grade was seen in 37 patients, whereas change by two grades was seen with 3 patients.

With $\mathrm{McCoy}^{\mathrm{TM}}$ laryngoscope, 35 patients had improved glottic view after activating lever; change in glottic view by one grade was seen in 24 patients, whereas change by two grades in 11 patients.

The change in glottic view was consistently towards an improved visualisation in all patients.

Ease of intubation between two laryngoscopes is compared. (Table 4) Intubation grade of 1 was observed in 49 patients intubated with Macintosh laryngoscope and 53 patients intubated with $\mathrm{McCoy}^{\mathrm{TM}}$ laryngoscope. Intubation grade of 2 was seen in 21 patients intubated with Macintosh and 17 patients with $\mathrm{McCoy}^{\mathrm{TM}}$ laryngoscopes. None of the patients required more than one attempt at intubation.

Laryngoscopy time as well as intubation time between two laryngoscopes is compared. (Table 5) Laryngoscopy time between two laryngoscopes was statistically significant ( $p=0.007$ ). However, it is clinically insignificant, as the difference is nearly by one second. Intubation time between two 
laryngoscopes was both statistically and clinically not significant.

Table 1: Comparison of glottic view before and after OELM with Macintosh laryngoscope

\begin{tabular}{|c|c|c|c|c|c|c|c|c|}
\hline & \multicolumn{6}{|c|}{ Glottic view after OELM } & \multirow{2}{*}{$\begin{array}{l}\text { No. of } \\
\text { patient } \\
\mathrm{s} \\
(\mathrm{n}=14 \\
\text { 0) }\end{array}$} \\
\hline & & 1 & $2 a$ & $2 b$ & $3 a$ & $3 b$ & 4 & \\
\hline \multirow{6}{*}{ 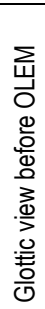 } & 1 & 100 & 0 & 0 & 0 & 0 & 0 & 100 \\
\hline & $2 a$ & 26 & 0 & 0 & 0 & 0 & 0 & 26 \\
\hline & $2 b$ & 3 & 9 & 0 & 0 & 0 & 0 & 12 \\
\hline & $3 a$ & 0 & 0 & 2 & 0 & 0 & 0 & 2 \\
\hline & $3 b$ & 0 & 0 & 0 & 0 & 0 & 0 & 0 \\
\hline & 4 & 0 & 0 & 0 & 0 & 0 & 0 & 0 \\
\hline & Total & 129 & 9 & 2 & 0 & 0 & 0 & 140 \\
\hline
\end{tabular}

Table 2: Comparison of glottic view before and after use of lever with $\mathrm{McCoy}{ }^{\mathrm{TM}}$ laryngoscope

\begin{tabular}{|c|c|c|c|c|c|c|c|c|}
\hline & \multicolumn{6}{|c|}{ Glottic view after use of lever } & \multirow{2}{*}{$\begin{array}{ll}\text { No. of } \\
\text { patients } \\
(n=140)\end{array}$} \\
\hline & & 1 & $\begin{array}{l}2 \\
a\end{array}$ & $\begin{array}{l}2 \\
b\end{array}$ & $3 a$ & $3 b$ & 4 & \\
\hline \multirow{4}{*}{ 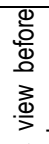 } & 1 & 105 & 0 & 0 & 0 & 0 & 0 & 105 \\
\hline & $2 a$ & 20 & 0 & 0 & 0 & 0 & 0 & 20 \\
\hline & $2 \mathrm{~b}$ & 9 & 4 & 0 & 0 & 0 & 0 & 13 \\
\hline & $3 a$ & 0 & 2 & 0 & 0 & 0 & 0 & 2 \\
\hline \multirow{2}{*}{$\begin{array}{l}\text { 음 } \\
\text { 은 }\end{array}$} & $3 b$ & 0 & 0 & 0 & 0 & 0 & 0 & 0 \\
\hline & 4 & 0 & 0 & 0 & 0 & 0 & 0 & 0 \\
\hline \multicolumn{2}{|c|}{ Total } & 134 & 6 & 0 & 0 & 0 & 0 & 140 \\
\hline
\end{tabular}

Table 3: Change in glottic view with Macintosh (before and after OELM) and $\mathrm{McCoy}^{\mathrm{TM}}$ laryngoscopes (before and after use of lever)

\begin{tabular}{|l|l|l|l|l|l|l|}
\hline $\begin{array}{l}\text { Change in } \\
\text { grade of glottic } \\
\text { view }\end{array}$ & $\begin{array}{l}2 \mathrm{a} \\
\rightarrow 1\end{array}$ & $\begin{array}{l}2 \mathrm{~b} \\
\rightarrow 1\end{array}$ & $\begin{array}{l}2 \mathrm{~b} \\
\overrightarrow{2 \mathrm{a}}\end{array}$ & $\begin{array}{l}3 \mathrm{a} \\
\overrightarrow{2 b}\end{array}$ & $\begin{array}{l}3 \mathrm{a} \\
\overrightarrow{2 \mathrm{a}}\end{array}$ & $\begin{array}{l}\text { Total no. } \\
\text { of } \\
\text { patients }\end{array}$ \\
\hline $\begin{array}{l}\text { Macintosh } \\
\text { laryngoscope }\end{array}$ & 26 & 3 & 9 & 2 & 0 & 40 \\
\hline $\begin{array}{l}\text { McCoy } \\
\text { laryngoscope }\end{array}$ & 20 & 9 & 4 & 0 & 2 & 35 \\
\hline
\end{tabular}

Table 4: Comparison of ease of intubation

\begin{tabular}{|l|l|l|l|l|}
\hline \multirow{2}{*}{ Laryngoscope } & \multicolumn{3}{|l|}{ Intubation grades } \\
\cline { 2 - 5 } & 1 & 2 & 3 & 4 \\
\hline $\begin{array}{l}\text { Macintosh } \\
(n=70)\end{array}$ & 49 & 21 & 0 & 0 \\
\hline $\begin{array}{l}\text { McCoy } \\
(n=70)\end{array}$ & 53 & 17 & 0 & 0 \\
\hline
\end{tabular}

Table 5: Comparison of laryngoscopy time and intubation time between Macintosh and $\mathrm{McCoy}^{\mathrm{TM}}$ laryngoscopes

$\mathrm{n}=$ number of patients, $\mathrm{SD}=$ standard deviation *Unpaired t-test

\begin{tabular}{|c|c|c|c|c|}
\hline Laryngoscope & $\begin{array}{l}\text { Laryngoscopy } \\
\text { time in } \\
\text { seconds } \\
(n=140) \\
\text { (Mean } \pm \text { SD) }\end{array}$ & $\begin{array}{l}\text { p value for } \\
\text { laryngoscopy } \\
\text { time* }\end{array}$ & $\begin{array}{l}\text { Intubation } \\
\text { time in } \\
\text { seconds } \\
(n=70) \\
\text { (Mean } \pm \\
\text { SD) }\end{array}$ & $\begin{array}{l}p \text { value } \\
\text { for } \\
\text { intubati } \\
\text { on } \\
\text { time* }\end{array}$ \\
\hline Macintosh & $6.02 \pm 1.91$ & \multirow[t]{2}{*}{0.007} & $\begin{array}{l}15.24 \pm \\
3.01\end{array}$ & \multirow[t]{2}{*}{0.120} \\
\hline McCoy & $6.65 \pm 2.09$ & & $\begin{array}{l}16.09 \pm \\
3.42\end{array}$ & \\
\hline
\end{tabular}

\section{Discussion}

The $\mathrm{McCoy}^{\mathrm{TM}}$ laryngoscope, a modification of the conventional Macintosh laryngoscope was introduced in 1993. ${ }^{2,8}$ The hinged tip of $\mathrm{McCoy}^{\mathrm{TM}}$ laryngoscope flexes upwards after activation of lever, thereby lifting epiglottis out of view to expose more of glottis. The levering action of McCoy laryngoscope on glottic view was studied by different authors, yielding contradictory results. ${ }^{9,10,11}$ Glottic view may worsen or improve when the lever was activated. Release of the lever is recommended when glottic view wasworsened. ${ }^{12}$ Whenever glottic view is poor, manoeuvres like OELM may also improve the view. ${ }^{13,14,15}$

In this study, we compared the Macintosh and $\mathrm{McCoy}^{\mathrm{TM}}$ laryngoscopes with respect to glottic view and ease of endotracheal intubation. The study population was divided into two groups with 70 patients in each group. Glottic view was assessed as CL grading. None of the patients in both groups had $\mathrm{CL}>3 \mathrm{a}$ view. Glottic view obtained with both laryngoscopes were similar and comparable. (Table $1,2)$ In addition, glottic view after OELM and lever with Macintosh and $\mathrm{McCoy}^{\mathrm{TM}}$ laryngoscopes 
respectively, were almost similar. The change in glottic view with OELM /use of lever was towards improved visualization in all patients. Change in glottic view by one CL grade was observed more often in patients after OELM, whereas change by two CL grade was seen in more patients with use of lever. (Table 3) Ease of intubation were similar with two laryngoscopes. (Table 4) Laryngoscopy time between two laryngoscopes although statistically significant (Table $5, \mathrm{p}=0.007$ ), was clinically not significant as the difference is nearly by one second. Intubation time between two laryngoscopes was comparable and was statistically as well as clinically not significant.

None of the patients from both groups had any airway related complications, As the observer 2 was same anaesthesiologist who did laryngoscopy and intubation in all cases, we could minimise interobserver bias.

There were few limitations in our study. Ease of intubation could not be compared in the same patient with two laryngoscopes because of ethical issues. Patients with anticipated difficult airway were excluded and therefore majority of the patients had good laryngeal view without need for any additional manoeuvres. It was not possible to blind observer 2. The grading of glottic view was subjective. The results of this study cannot be extrapolated to patients with difficult airway and inexperienced anaesthesia providers.

\section{Conclusion}

In adult patients with essentially normal airway, both Macintosh and $\mathrm{McCoy}^{\mathrm{TM}}$ laryngoscopes provide similar glottic view and ease of intubation with appropriate use of optimum external laryngeal manipulation and lever respectively. Optimal external laryngeal manipulation and use of lever consistently provide better glottic view with Macintosh and $\mathrm{McCoy}^{\mathrm{TM}}$ laryngoscopes respectively, whenever initial view is higher than Cormack-Lehane grade 1. Laryngoscopy time and intubation time are comparable between Macintosh and $\mathrm{McCoy}^{\mathrm{TM}}$ laryngoscopes, without superiority of any one over the other.

\section{References}

1. Dorsch JA, Dorsch SE. Laryngoscopes. In: Dorsch JA, Dorsch SE, editors. Understanding Anesthesia
Equipment. 5th ed. Lippincott Williams and Wilkins; 2011. p. 521-60.

2. McCoy EP, Mirakhur RK. The levering laryngoscope. Anaesthesia1993;48:516-9.

https://doi.org/10.1111/j.1365-

2044.1993.tb07075.x

3. Ward M. The McCoy levering laryngoscope blade. Anaesthesia1994;49:357-8.

https://doi.org/10.1111/j.1365-

2044.1994.tb14209.x

PMid:8179160

4. Gabbott DA. Laryngoscopy using the McCoy laryngoscope after application of a cervical collar. Anaesthesia1996;51:812-4.

https://doi.org/10.1111/j.1365-

2044.1996.tb12606.x

PMid:8882239

5. Uchida T, Hikawa Y, Saito Y, Yasuda K. The McCoy levering laryngoscope in patients with limited neck extension. Can J

Anaesth1997;44:674-6. https://doi.org/10.1007/BF03015455 PMid:9187791

6. Ali QE, Das B, Amir SH, Siddiqui OA, Jamil S. Comparison of the Airtraq and McCoy laryngoscopes using a rigid neck collar in patients with simulated difficult laryngoscopy. J Clin Anesth2014;26:199-203. https://doi.org/10.1016/j.jclinane.2013.10.012 PMid:24809787

7. Cook TM. A new practical classification of laryngeal view. Anaesthesia 2000;55:274-9. https://doi.org/10.1046/j.1365-2044.2000.01270.x PMid:10671848

8. Tuckey JP, Cook TM, Render CA. An evaluation of the levering laryngoscope. Anaesthesia 1996:51:713.

https://doi.org/10.1111/j.1365-

2044.1996.tb07658.x

PMid:8669571

9. Cook TM, Tuckey JP. A comparison between the Macintosh and the McCoy laryngoscope blades. Anaesthesia1996;51:977-80.

https://doi.org/10.1111/j.1365-

2044.1996.tb14971.x

10. Pritchard C. Comparison of the Macintosh and McCoy laryngoscope blades.

Anaesthesia1997;52:185-6.

11. Levitan RM, Ochroch EA. Explaining the variable effect on laryngeal view obtained with the McCoy laryngoscope. Anaesthesia1999;54:599-601. https://doi.org/10.1046/j.1365-2044.1999.96794.x

12. Chisholm DG, Calder I. Experience with the McCoy laryngoscope in difficult laryngoscopy. Anaesthesia1997;52:906-8. 
Muhamed et al. Sri Lankan Journal of Anaesthesiology: 27(21):151-156(2019)

https://doi.org/10.1111/j.1365-2044.1997.196-

az0329.x

13. Benumof JL, Cooper SD. Quantitative improvement in laryngoscopic view by optimal external laryngeal manipulation. J Clin

Anesth1996;8:136-40.

https://doi.org/10.1016/0952-8180(95)00198-0

14. Harioka T, Nomura K, Mukaida K, Hosoi S, Nakao S. The McCoy laryngoscope, external laryngeal pressure, and their combined use. Anaesth Intensive Care 2000;28:537-9.

https://doi.org/10.1177/0310057X0002800509

PMid:11094670 